\title{
Analysis of Space-Ground Integrated Information Network Architecture and Protocol
}

\author{
Yong Zhou ${ }^{1, a^{*}}$,Chundong She ${ }^{2, b}$, Ligang Fei ${ }^{3}$ and Kaiming Liu ${ }^{2}$ \\ ${ }^{1}$ Beijing institute of information and control, Fucheng road, Beijing, China \\ ${ }^{2}$ Beijing University of Posts and Telecommunications, Beijing, China \\ ${ }^{3}$ Beijing Space Information Relay Transmission Technology Research Center \\ ashurcd@vip.sina.com, ${ }^{b}$ scd@bupt.edu.cn
}

Keywords: Network Architecture; Network Protocol; Backbone network.

Abstract. As the core carrier of information acquisition, distribution, transmission and application in the future, Space-Ground Integrated Information Network（SGIIN） will play a very important role in the development of national economy and society. Operation environment and the diversity application of SGIIN put forward the challenge of network architecture and protocol. On the basis of the characteristics of SGIIN, in this paper, the two level network-backbone network and secondary access network architecture was given, and the performance of transmission protocol and routing protocol are analyzed.

\section{Introduction}

With the development of technology and the diversification of application requirements, isolated satellite system which has the single function, regular structure and operation relied on the ground can not meet the service demand of real-time and comprehensive. The heterogeneous satellite network provided with multiple functions, complementary tracks, high intelligence, autonomous operation and scalability becomes a new development direction.

SGIIN: Space-Ground Integrated Information Network[1], called integrated information network, as shown in Figure 1, is composed of heterogeneous satellite/satellite networks with communication, reconnaissance, navigation, weather and other functions, space vehicles and ground wire and wireless network equipment. It can be the integration of existing satellite systems on demand, as well as the result of the "integrated" design. This highly integrated heterogeneous network system breaks the barriers of data sharing among different network systems.

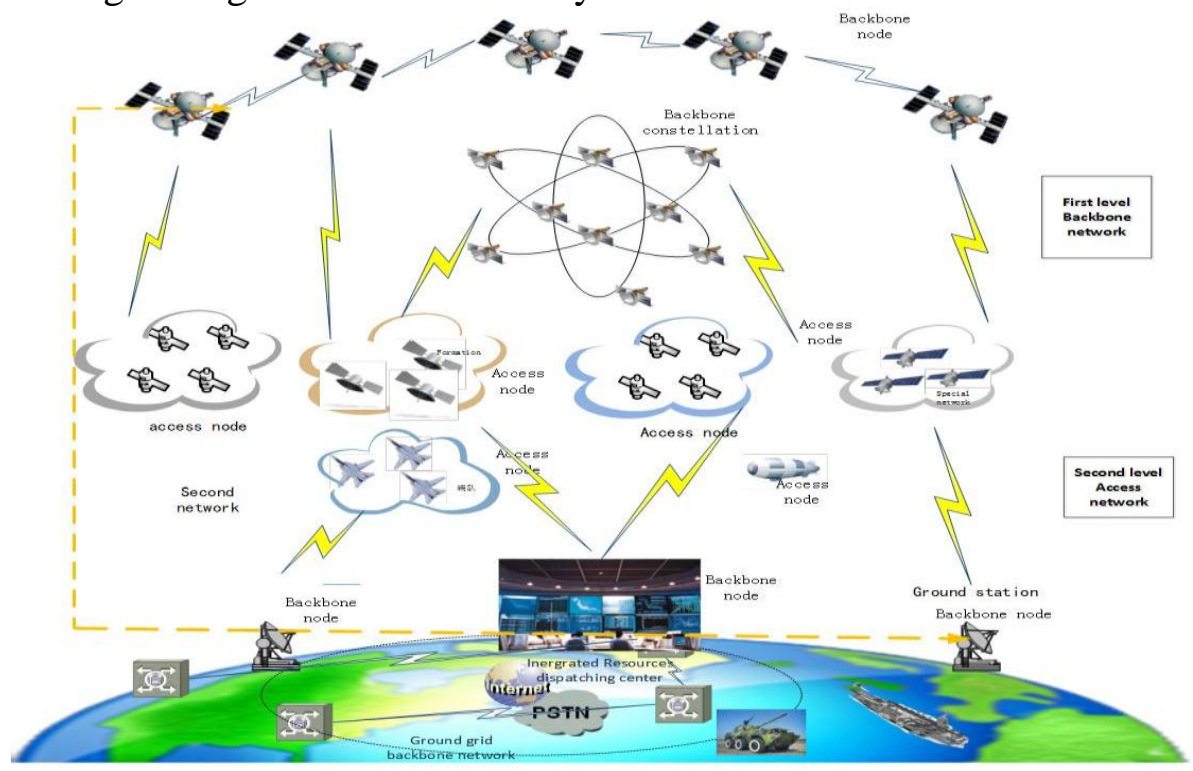

Fig. 1 SGIIN-two level architecture 


\section{Construction of Protocol Architecture of SGIIN}

The commonly used protocol architectures including TCP/IP, CCSDS [2], DTN [3] and SDN. TCP/IP are widely used in ground Internet network, but because the communication environment in satellite network and ground Internet has difference, TCP/IP can not be applied to SGIIN; CCSDS is the space communication protocol standard for the characteristics of space communication, its communication scheme is feasible, but needs to optimize the design of the transmission and routing; DTN is a special network, it is suitable for space environment characteristics, but due to the wrapping layer and convergence layer, leads to some compatibility problems of the protocol with the ground and other network; SDN is a new type of network technology, its seperated network control and forwarding capability leads user to control forwarding capability directly by programming. SDN technology can enhance the edge forwarding capability of the control layer, the high carrying capacity of the backbone network and the open interoperability. But its forwarding equipments are very complex, and there is no uniform standard.

SGIIN is a complex giant system. From the view of construction, such a system includes not only the exist systems, but also the unconstructed system, the operating mode and the protocol are not the same between the system. Based on the actual construction needs, we propose two level network architecture to build the system, as shown in Fig.1. Among the system, the first level network (backbone network) node mainly refers to the backbone transmission role of nodes, including the broadband satellite, relay satellite and ground network backbone router; second network (access network) node is to complete specific tasks such as information required satellite, small satellite formation network, special constellation, the non-backbone nodes in ground network. This network architecture can improve the efficiency of information transmission and reduce the complexity of routing and access of SGIIN.

For backbone network, in order to interconnect with heterogeneous network, the standard hierarchical protocol was adopted. For the access network, the protocol architecture can used the special network, such as unstructured network etc.[4]. This is mainly to ensure the efficiency of the two level network. As shown in Fig. 2.

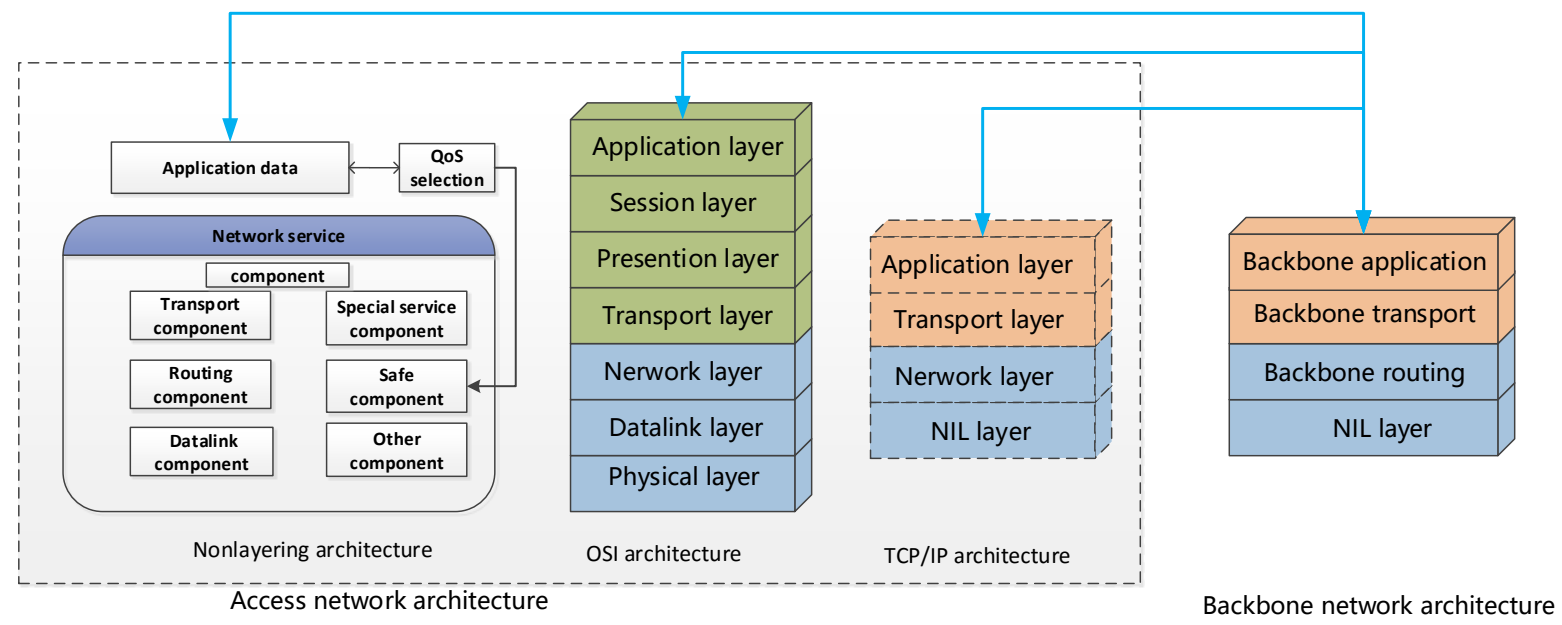

Fig.2. SGIIN backbone network and access network protocol architecture

In order to be compatible with the ground and other networks, this protocol architecture includes a common protocol stack, and some protocols specifically designed for space-based backbone network such as BTP, BNP, BRP and broadband access protocols, security authentication protocols, etc.. In the actual transmission, the protocol stack can be optimized according to the specific transmission requirements, aim to achieve efficient transmission.

Access network protocol architecture can be selected on demand, it can be hierarchical protocol, or non-hierarchical protocol architecture, such as: DTN,TCP/IP, CCSDS, SDNand component-based protocol architecture, and so on. Deep space network node can choose DTN, the ground network can select TCP / IP, the satellite cluster network can use component-based protocol architecture. 


\section{Transmission and Routing Protocol Analysis}

\section{Transport protocol analysis}

As shown in Fig.3, the test bed environment consists of two separate networks, representing the ground network and the space network separately. The two networks are connected by multiple networks, simultaneously going through a channel simulator which could achieve delay and random bit errors of network data stream settings. The network at each end of the channel consists of a router and an Ethernet switch.

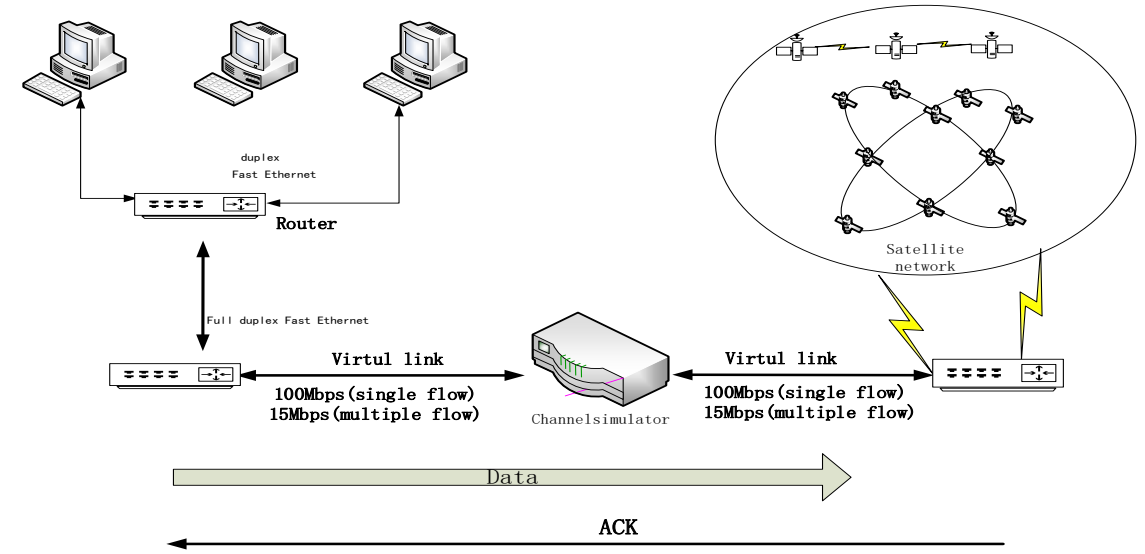

Fig.3. Test bed environment

Fig. 4 and Fig. 5 are protocol performance based on the congestion control. Fig. 4 shows the average throughput of different transport protocols for transmitting $10 \mathrm{MB}$, and $100 \mathrm{MB}$ files in the case of 500ms delay. Fig. 5 shows the average throughput of different protocols for transmitting 10MB files under different BER conditions. Fig. 6 and Fig. 7analyze the protocol performance based on the rate control.

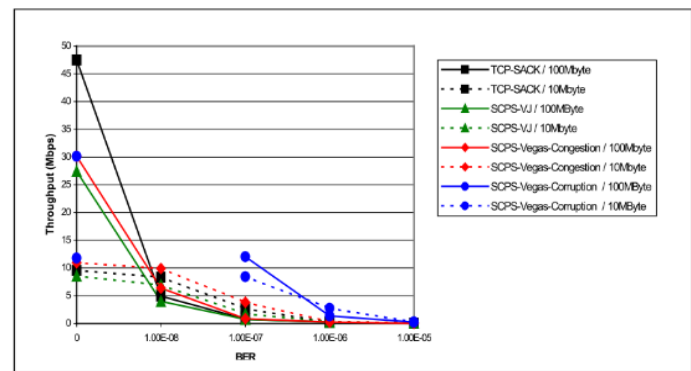

Fig.4. Protocol performance based on the Congestion control (500ms delay)

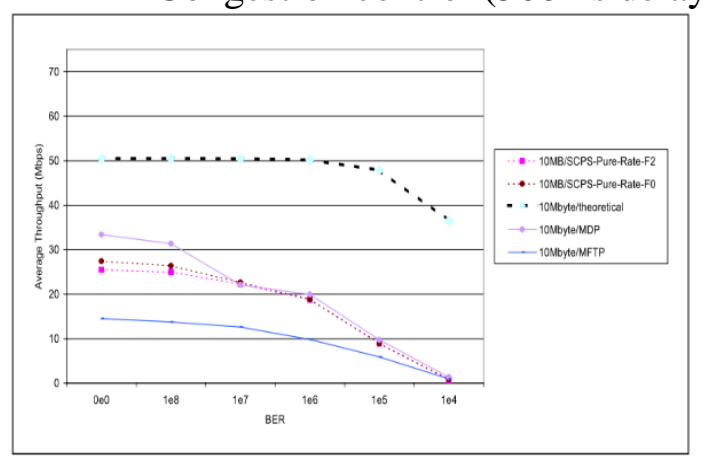

Fig.6. Rate-based file transmission(500ms delay)

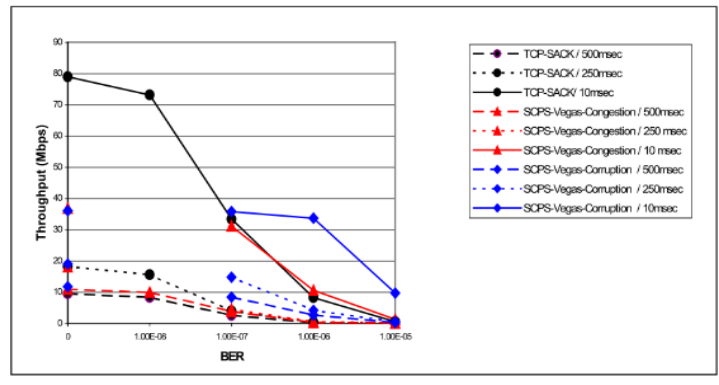

Fig.5. Average throughput of different protocols (10MB file transmittion)

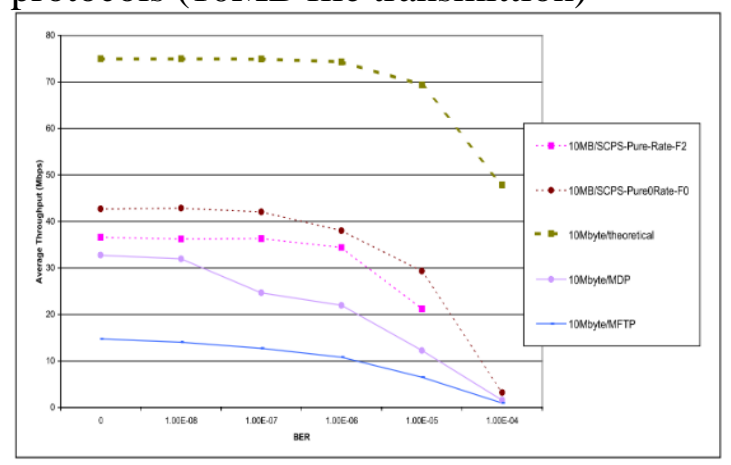

Fig.7. Comparision of rate-based average throughput and BER(10ms delay) 
The analysis of the above results shows:

1)In the space environment, multiple data stream (Fig.4-5) and single data stream (Fig.6-7) test results showed SCPS-Vegas on the TCP enhancements can provide performance improvements.

2)In the condition of high RTT delay, namely in high RTT delay error sensitive environment, rate-based control protocol performance is significantly decreased. Although the existing congestion transmission protocol can meet the demands of most of the tasks, it still needs to be modified and optimized.

\section{Routing protocol analysis}

The satellite network routing protocol makes full use of the periodicity and predictability of satellite network topology, and can reduce the network resources consumption of routing protocols, so that the routing protocol is limited by the satellite network topology, Once the satellite network topology changes, such as adding new nodes, new tracks, new constellation, the routing protocol need to make enormous changes, have not strong scalability.

According to the characteristics of satellite networks transport tasks, the performance of satellite network routing algorithm is analyzed from three aspects: data packet forwarding, system complexity and portability. Data packet forwarding mainly include delay, robustness, stability, correctness, fairness, optimality, other performance indexes. The data packet forwarding comparison of satellite network routing algorithms is shown in Table 1. System complexity and portability is not discussed here due to space limitations.

Satellite network routing algorithm based on a sequence of discrete topologies will first establish a virtual link between satellite nodes, then select the path with smaller delay and less switching as the optimal path among alternative paths, theoretically delay jitter is small, but the actual operation of the network process, smaller delay and less switching may be two conflicting conditions, so using the satellite network routing algorithm based on a sequence of discrete topologies during the actual operation, the delay jitter is often larger than the theoretical analysis.

Location-based satellite network routing algorithm does not use virtual connections, due to the path selection uncertainty, delay jitter can not be guaranteed. Delay jitter is relatively serious. Based on Ekici distributed satellite network routing, Location-based distributed survivable routing algorithm prefer neighbors closer to the target location as the next hop, it can obtain better end-to-end delay results. 


\begin{tabular}{|c|c|c|c|c|}
\hline $\begin{array}{l}\text { Satellite } \\
\text { network } \\
\text { routing } \\
\text { algorithm }\end{array}$ & Performance & $\begin{array}{l}\text { Delay } \\
\text { jitter }\end{array}$ & Stability and robustness & Fairness and optimality \\
\hline \multirow{3}{*}{$\begin{array}{l}\text { Satellite } \\
\text { network } \\
\text { routing } \\
\text { algorithm } \\
\text { based on a } \\
\text { sequence of } \\
\text { discrete } \\
\text { topologies }\end{array}$} & $\begin{array}{l}\text { ATM-based } \\
\text { satellite } \\
\text { network } \\
\text { routing } \\
\text { algorithm }\end{array}$ & Worse & $\begin{array}{l}\text { Using virtual channel mechanism, the } \\
\text { connection oriented transmission mode is } \\
\text { relatively stable. However, the update of } \\
\text { the routing table has the timeliness } \\
\text { problem. When the satellite and the } \\
\text { ground communication difficulties or just } \\
\text { resume, the obsolete routing table easily } \\
\text { lead to problems. When the satellite link is } \\
\text { invalid or controlled, it needs the ground } \\
\text { to make a quick response, recalculate and } \\
\text { update the satellite routing link. }\end{array}$ & $\begin{array}{l}\text { The optimal routing path } \\
\text { returning to the satellite, } \\
\text { which is calculated by the } \\
\text { ground based on the network } \\
\text { topology the ground, is not } \\
\text { considered fairly, but the } \\
\text { delay and the number of } \\
\text { switches are small. The } \\
\text { optimal path had not } \\
\text { considered real-time, and is } \\
\text { not necessarily optimal. }\end{array}$ \\
\hline & $\begin{array}{l}\text { FSA-based } \\
\text { satellite } \\
\text { network } \\
\text { routing } \\
\text { algorithm }\end{array}$ & Good & $\begin{array}{l}\text { The problem is same with the ATM-based } \\
\text { mechanism. But for special circumstances, } \\
\text { the processing is not timely. The } \\
\text { robustness needs to further strengthen. }\end{array}$ & $\begin{array}{l}\text { The Stability and robustness } \\
\text { is similar with the ATM } \\
\text { mechanism, but due to } \\
\text { introducing the traffic } \\
\text { constraint, this algorithm is } \\
\text { suitable for the fairness and } \\
\text { the optimality. }\end{array}$ \\
\hline & $\begin{array}{l}\text { snapshot } \\
\text { based } \\
\text { satellite } \\
\text { routing } \\
\text { algorithm }\end{array}$ & General & $\begin{array}{l}\text { On the basis of the ATM mechanism, the } \\
\text { algorithm added alternative path, the path } \\
\text { was selected along with the satellite } \\
\text { switching optimization, then the stability is } \\
\text { enhanced. Due to limited routing table } \\
\text { data, delay is still existing and robustness } \\
\text { is unsatisfactory. }\end{array}$ & $\begin{array}{l}\text { Introducing the alternative } \\
\text { path and selecting the path } \\
\text { along with switching } \\
\text { optimization, the serious error } \\
\text { is avoided, and the serious } \\
\text { decline of optimality can be } \\
\text { alleviated }\end{array}$ \\
\hline \multirow{3}{*}{$\begin{array}{l}\text { Location-based } \\
\text { satellite } \\
\text { network } \\
\text { routing } \\
\text { algorithm }\end{array}$} & $\begin{array}{l}\text { IP-based } \\
\text { satellite } \\
\text { network } \\
\text { routing } \\
\text { algorithm }\end{array}$ & Better & $\begin{array}{l}\text { The stability is not enough for the } \\
\text { non-connected transmission mode. The } \\
\text { algorithm could real time search according } \\
\text { to different circumstances, and fast } \\
\text { response for the special circumstances, } \\
\text { which enhance the robustness of the } \\
\text { algorithm. But it has relatively high } \\
\text { dependence on geographic location, so } \\
\text { local processing can not solve the global } \\
\text { problem. }\end{array}$ & $\begin{array}{l}\text { Selecting the path according } \\
\text { to the real-time situation, The } \\
\text { algorithm attach importance } \\
\text { to the efficiency, the local } \\
\text { processing fairness and } \\
\text { optimality, but the local } \\
\text { optimality may not be the } \\
\text { global optimality. }\end{array}$ \\
\hline & $\begin{array}{l}\text { Ekici } \\
\text { distributed } \\
\text { satellite } \\
\text { network } \\
\text { routing } \\
\text { algorithm }\end{array}$ & Better & $\begin{array}{l}\text { The algorithm is basically the same with } \\
\text { IP-based satellite network routing } \\
\text { algorithm. The spherical space and polar } \\
\text { processing are introduced, which makes } \\
\text { the satellite path considered more } \\
\text { practical. But the characteristics of the } \\
\text { distributed algorithm still determined that } \\
\text { its treatment measures are not necessarily } \\
\text { able to solve the global situation. }\end{array}$ & $\begin{array}{l}\text { Basically consistent with } \\
\text { IP-based routing algorithm, } \\
\text { the optimality of the algorithm } \\
\text { is further enhanced by } \\
\text { considering the spherical and } \\
\text { polar regions. }\end{array}$ \\
\hline & $\begin{array}{l}\text { Distributed } \\
\text { survivable } \\
\text { routing } \\
\text { algorithm } \\
\text { based on } \\
\text { geographical } \\
\text { location }\end{array}$ & Better & $\begin{array}{l}\text { The algorithm can real-time control the } \\
\text { satellite status near the four nodes, and } \\
\text { strive to the fastest processing of special } \\
\text { circumstances, with a very good } \\
\text { robustness. At the same time, although the } \\
\text { non connection oriented mode is used, } \\
\text { introducing the weight of comparative law } \\
\text { and the invulnerability make the } \\
\text { transmission stability better. }\end{array}$ & $\begin{array}{l}\text { Inheriting the characteristics } \\
\text { of the IP-based satellite } \\
\text { network routing algorithm, } \\
\text { and the processing of the seam } \\
\text { and the polar region, the } \\
\text { algorithm introduced the } \\
\text { weight determination } \\
\text { mechanism, and strengthened } \\
\text { the optimality. }\end{array}$ \\
\hline
\end{tabular}

Table 1 Comparison of packet forwarding of satellite network routing algorithm 


\section{Summary}

Through the analysis of different protocol architectures, we believe that the CCSDS protocol can be as the future space-based backbone network protocol architecture, however, the functions of transmission layer, network layer and link layer should be modified and optimized adaptability to meet the requirements of the integrated transmission.

\section{Acknowledgements}

This work was supported by the National Natural Science Foundation of China (91438120) and the Foundation of Key Laboratory of Aerospace Broadband Network Technology.

\section{References}

[1] Lixiang Liu. Space-Ground Integrated Information Network, Science Press, 2015.(In Chinese )

[2] Space Communications Protocol Standards (SCPS). http://www.scps.org.

[3] V. Cerf, S. Burleigh, A. Hooke, et al. Delay-Tolerant Networking Architecture, IETFRFC 4838, informational, April 2007.

[4] M. Chiang, S. H. Low, A. R. Calderbank, et al. Layering as Optimization Decomposition: A Mathematical Theory of Network Architectures, Proceedings of the IEEE, 2007, 95(1):255-312. 